\title{
Avaliação das Exigências da Lei 8399/2005 para a Adequação das Edificações Construídas Antes 29/08/1984 - Complexo Biblioteca e Reitoria UFMT
}

\section{Evaluation of Law 8399/2005 Requirements for the Adequacy of Buildings Built Before 08/29/1984 - Complex Library and Regents UFMT}

\author{
${ }^{1}$ Larissa Rodrigues Turini, ${ }^{2}$ Gonçalo Baicere
}

${ }^{1}$ Graduada em Engenharia Sanitária e Ambiental, formanda da Especialização Segurança do Trabalho ${ }^{2}$ Docente do curso de graduação em Engenharia Sanitária e Ambiental

Enviado em: abril de 2016. Aceito em: maio de 2016. Publicado em: novembro de 2016

\begin{abstract}
RESUMO: Os sistemas de prevenção e combate à incêndio e pânico, são compostos de equipamentos ativos ou passivos, que agem na extinção do fogo, ou impedem que este se propague para outro ambiente. Visando avaliar a segurança dos usuários e do acervo contido no Bloco que abriga a Biblioteca Central e a Reitoria da UFMT Campus Cuiabá, este trabalho objetiva verificar se a edificação está em conformidade com a Lei 8399/2005 Lei de Segurança Contra Incêndio e Pânico de Mato Grosso, para as construções edificadas antes de 29/08/1984 e posteriores a esta data. Foram realizadas vistorias em todos os setores da edificação, e ficou comprovado que os equipamentos preventivos da edificação não estavam em conformidade com as exigências da Lei 8399/2005, sendo necessário a correção imediata destas inconformidades na edificação.
\end{abstract}

Palavras-chave:Acidente. Pânico. Legislação. Edificação.

\begin{abstract}
The prevention systems and fire fighting and panic, are composed of active or passive devices, which act in extinguishing the fire, or prevent this from spreading to another environment. To evaluate the safety of users and the acquis contained in the block which houses the Central Library and the Dean of UFMT Campus Cuiabá, this study aims to verify whether the building is in accordance with the Law 8399/2005 - Security Law Fire and Panic Mato Grosso, for buildings constructed before 29.8.1984 and subsequent to this date. surveys were carried out in all sectors of the building, and it was proved that preventive equipment of the building did not comply with the requirements of Law 8399/2005, the requiring immediate correction of these nonconformities in the building.
\end{abstract}

Keywords: Accident. Panic. Legislation. Edification.

\section{INTRODUÇÃ̃O}

A área de segurança contra incêndio ganhou impulso no Brasil, nas décadas de 70 e 80, quando ocorreram acidentes de grandes proporções. Os quais trouxeram acontecimentos trágicos, com perdas inestimáveis e marcas indestrutíveis (FREIRE, 2009).

O incêndio é a ocorrência do fogo sem controle, que independe de condições geográficas, econômicas ou políticas, podendo tomar proporções devastadoras, causando perdas e danos irrecuperáveis, sua ocorrência pode ser extremamente perigosa aos seres vivos e estruturas edificadas (LEITE E ASSIS, 2009). As duas principais causas são devido ao desconhecimento dos reais riscos de incêndio e ao descaso na previsão de medidas de segurança (MELO, 1999). 
A Prevenção Contra Incêndio consiste em uma exigência legal com intuito de salvar vidas e bens materiais, reduzir as possibilidades de ocorrência e minimizar a propagação do fogo. As pessoas de uma edificação, seja de sua residência ou local de trabalho, devem ser instruídas para enfrentar uma situação de incêndio, seja adotando medidas para controlar o princípio de incêndio, através da utilização dos sistemas preventivos instalados para esse fim, como: extintores, hidrantes, ou procedendo à evacuação do prédio de maneira rápida e ordenada, sem a instauração do pânico e não deixando nenhum ocupante para trás, por meio de conhecimento prévio da localização das saídas de emergência (NUNES, 2009).

As bibliotecas são tradicionalmente constituídas de material altamente combustível, os acervos, que ficam armazenados em estantes enfileiradas sobre múltiplas prateleiras, caracterizando a formação de área com material vulnerável a incêndio. De acordo com Ono (2004):

"o risco de incêndio em tais áreas pode ser muito alto, principalmente onde o acesso ao público é permitido. Esse tipo de edificação necessita de um projeto de segurança contra incêndio que permita a monitoração intensificada das áreas do acervo e a rápida detecção de um foco de incêndio, assim como um eficiente combate ao fogo".

O Bloco da Biblioteca e Reitoria foram edificados na década de 70 , com área construída de $5.383,42 \mathrm{~m}^{2}$, e altura de $5,45 \mathrm{~m}$.
Conforme a Lei 8399/2005 construções anteriores a 29/08/1984 com área construída $>750 \mathrm{~m}^{2}$ e/ou altura $>10 \mathrm{~m}$, devem ser compostos pelos preventivos: saída de emergência, alarme de incêndio, iluminação de emergência, extintores, sinalização e hidrantes. E posterior a esta data, além dos citados anteriormente: acesso de viaturas na edificação, segurança estrutural contra incêndio, controle de materiais de acabamento, plano de intervenção de incêndio, brigada de incêndio, detecção de incêndio, sinalização de emergência.

O objetivo geral é realizar uma análise comparativa, pois segundo a Lei Estadual 8.399 de 22 de dezembro de 2005, diz que, complexos construídos anteriores a 29 de agosto de 1984 devem conter determinados preventivos e após esta data as exigências são em número maiores.

O objetivo especifico é verificar se a edificação onde se encontra a Biblioteca Central e a Reitoria da Universidade Federal de Mato Grosso - UFMT, oferece segurança mesmo sendo uma edificação construída anterior a aprovação da Lei 8.399 .

\section{ÁREA DE ESTUDOS}

O prédio da Biblioteca e Reitoria localiza-se na Universidade Federal de Mato Grosso - Campus Cuiabá nas coordenadas geográficas $15^{\circ} 36^{\prime} 38,59^{\prime \prime} \mathrm{S} /$ $056^{\circ} 03^{\prime} 45,62^{\prime \prime} \mathrm{W}$. Localizado próximo a guarita com entrada pela Av.Alziro Zarur e em frente a Bloco de direito.

Segundo dados fornecidos pela universidade, o número de funcionários que trabalham na Biblioteca e Reitoria é de aproximadamente 100 pessoas, e a 
Turini L. R.; Baicere G., Avaliação das Exigências da Lei 8399/2005 para a Adequação das Edificações Construídas Antes 29/08/1984 - Complexo Biblioteca e Reitoria UFMT. E\&S - Engineering and Science, (2016), 5:2.

população que visita a Biblioteca é de aproximadamente 1.000 pessoas/ dia.

\section{MATERIAIS E METODOS}

A metodologia utilizada neste estudo foi realizada em três etapas: primeiramente o levantamento bibliográfico, seguido de coleta de dados nas edificações e por fim analise dos mesmos.

Os levantamentos bibliográficos foram realizados com base nas Normas Técnicas do Corpo de Bombeiros de Mato Grosso, livros técnicos.

Para a coleta de dados foram realizadas vistorias na Biblioteca e Reitoria que estão localizadas no mesmo prédio, sendo divididos apenas por divisórias.

Para realização do levantamento dos preventivos de combate e incêndio ativos e passivos da edificação, a Proplan forneceu a planta arquitetônica, que em função das adequações exigidas pela Lei 8.399 foram realizadas alterações do layout.

\section{RESULTADOS E DISCUSSÕES}

\section{Classificação da Edificação em Estudo}

O prédio em questão é constituído pela biblioteca e reitoria, como já abordado anteriormente. A Reitoria é composta por várias salas, banheiros, duas copas, e a Biblioteca por salas de leitura repletas de prateleiras com livros, banheiros, sala de funcionários. A maioria dos ambientes é separada por divisórias, aumentando consideravelmente a carga de incêndio da edificação.

O prédio possui cinco pavimentos, somando uma área total de $5.383,50 \mathrm{~m}^{2}$, com pé direito de $5,45 \mathrm{~m}$, medidos de piso a piso (do piso térreo ao piso do quinto pavimento).

As classificações foram realizadas de acordo com as Tabelas anexas a Lei $8399 / 2005$ conforme preconiza a NTCB 01/2008 - Procedimentos administrativos.
A biblioteca e reitoria segundo a Lei 8399/2005 serão classificadas de acordo com as seguintes Tabelas.

Tabela 1 - Classificação quanto ao tipo da ocupação.

CLASSIFICAÇÃO QUANTO Á OCUPAÇÃO

\begin{tabular}{cc}
\hline OCUPAÇÃO & DIVISÃO \\
REITORIA & D-1 \\
BIBLIOTECA & F-1 \\
\hline
\end{tabular}

A Tabela 1 mostra a classificação da edificação quanto a Ocupação / Divisão. A reitoria é classificada no grupo D como "serviço profissional", portanto na divisão D-1, descrita como "local para prestação de serviço profissional ou condução de negócios" e a Biblioteca no grupo F, como "local de reunião de público", na divisão F-1, descrita como "local de valor inestimável".

Tabela 2 - Classificação quanto à altura do prédio. CLASSIFICAÇÃO QUANTO Á ALTURA

\begin{tabular}{cc}
\hline OCUPAÇÃO & ALTURA \\
REITORIA & TIPO II - BAIXA \\
BIBLIOTECA & TIPO II - BAIXA \\
& \\
\hline
\end{tabular}

A edificação na parte da Reitoria possui altura de $3,50 \mathrm{~m}$ e na parte da Biblioteca Central de $5,45 \mathrm{~m}$, medida piso a piso, sendo ambas classificadas como edificação baixa com altura $\mathrm{H} \leq 6 \mathrm{~m}$.

Tabela 3 -Classificação quanto à carga de incêndio na edificação.
CLASSIFICAÇÃO QUANTO Á CARGA DE INCÊNDIO

\begin{tabular}{cc}
\hline OCUPAÇÃO & RISCO \\
REITORIA & Médio \\
BIBLIOTECA & Alto \\
\hline
\end{tabular}


A Instrução Técnica No07/2009, Carga de incêndio nas edificações e áreas de risco do Corpo de Bombeiros Militar do Estado de Mato Grosso, classifica a ocupação tipo D-1 (Reitoria) como risco médio (carga de incêndio de $700 \mathrm{MJ} / \mathrm{m}^{2}$ ), e ocupação tipo F-1 (Biblioteca) como risco alto (carga de incêndio de $2.000 \mathrm{MJ} / \mathrm{m}^{2}$ ). Portanto, o risco predominante da edificação em estudo é alto $(\geq 1.200$ $\mathrm{MJ} / \mathrm{m}^{2}$ ) conforme instrui a legislação pertinente sobre a predominância do maior risco.

\section{Preventivos}

A Lei 8399/2005 diz que construções anteriores a 29/08/1984 com área construída $>750 \mathrm{~m}^{2}$ e/ou altura $>10 \mathrm{~m}$, devem possuir os seguintes preventivos: saída de emergência, alarme de incêndio, iluminação de emergência, extintores, sinalização e hidrantes.

E após 29/08/1984 os preventivos necessários seriam: acesso de viaturas na edificação, segurança estrutural contra incêndio, controle de materiais de acabamento, saída de emergência, plano de intervenção de incêndio, brigada de incêndio, iluminação de emergência, detecção de incêndio, alarme de incêndio, sinalização de emergência, extintores e hidrantes.

Foi observado in loco, que a edificação em questão possuía apenas os preventivos de extintores e hidrantes, os quais se encontravam obstruídos e localizados de forma inadequada, estando as instalações elétricas em péssimas condições, não possuindo saídas de emergência. Desta forma, os ambientes da Biblioteca e Reitoria, não atendiam as exigências da Lei 8399/2005.

\section{Saída de emergência}

Quanto a Saída de Emergência, o prédio foi classificado de acordo com a NTCB 13/2013 - Saídas de emergência em edifícios, conforme a classificação, o Bloco da Biblioteca deverá ter duas Escadas Protegidas, cada escada deverá ter largura de $1,90 \mathrm{~m}$, e ser protegida por paredes com resistência ao fogo, e munidas de portas corta fogo (PCF 90).

$\mathrm{Na}$ sala da hemeroteca a porta a ser executada deverá ter largura de $1,50 \mathrm{~m}$, abrindo para fora, com barra anti-pânico. E para a Reitoria, a qual também foi classificada conforme NBR 9077/2001, deverá ter duas Escadas Não Enclausuradas, onde cada escada deverá ter largura de $1,20 \mathrm{~m}$, e a porta do piso térreo deverá ter largura de $0,90 \mathrm{~m}$, abrindo para fora, com barra anti-pânico.

\section{Detecção e Alarme de incêndio}

Foi constatado que a edificação não possui sistema de detecção e alarme de incêndio, conforme exigência da Lei 8.399/2005.

O Sistema de Detecção e Alarme de incêndio, consiste na execução de instalações, operação e manutenção, conforme NBR17240/2010, que irão fornecer informações de princípios de incêndio, por meio de indicações sonoras e/ou visuais.

O mesmo será realizado através de acionadores manuais instalados em locais com trânsito de pessoas, com fácil visualização e acesso em caso de sinistro, a uma altura de $1,20 \mathrm{~m}$ do piso acabado, atendendo uma distância a percorrer de no máximo $15 \mathrm{~m}$.

A Central de alarme de incêndio responsável pela supervisão de toda edificação deverá ser instalada na Recepção da Reitoria, a qual deverá ser monitorada durante 24 horas por dia, por operador treinado, instalada a 2,00 metros de altura.

Considerando o que preconiza a legislação vigente, o sistema alarme será do tipo endereçável composto de 20 unidades.

Serão utilizados no sistema de detecção em questão, detectores de fumaça 
iônicos, com área de atuação de aproximadamente $80 \mathrm{~m}^{2}$ cada. Estes detectores serão instalados no teto e convenientemente localizados a fim de obter-se o maior nível de proteção proporcionado por eles.

Considerando o que preconiza a legislação vigente, o sistema detecção projetado será do tipo endereçável.

\section{Iluminação de emergência}

Foi constatado que a edificação não possui sistema de iluminação de emergência, conforme exigência da Lei 8.399/2005.

O Sistema de Iluminação de emergência deverá ser elaborado e executados conforma NBR10898/1999.

\section{Extintor de incêndio}

Os extintores serão instalados a $1,80 \mathrm{~m}$ do piso acabado (altura máxima). De acordo com a ocupação do ambiente serão especificados os tipos de extintores a serem instalados.

Diante das vistorias realizadas in loco e com base no Decreto 857/1984, os extintores encontrados e os necessários para a proteção dos pavimentos, são os seguintes:

- Primeiro Piso - Biblioteca: possui 1 extintor de PQS $4 \mathrm{Kg}$. Para este setor seriam necessários 3 extintores de água pressurizada, 10 L, e 1 de gás carbônico, $6 \mathrm{Kg}$.

- Segundo piso - parte Biblioteca: possui 8 extintores, sendo 3 águas pressurizada $10 \mathrm{~L}, 2 \mathrm{CO}_{2} 6 \mathrm{Kg}$ e 3 PQS 4Kg.Para este setor seriam necessários 4 extintores de água pressurizada, $10 \mathrm{~L}$, e 4 de gás carbônico, $6 \mathrm{Kg}$.

- Segundo Piso - Reitoria: possui 2 unidades, sendo 1 extintor de água pressurizada $10 \mathrm{~L}$ e 1 de $\mathrm{CO}_{2} 6 \mathrm{Kg}$. Para este setor seriam necessários 3 extintores, sendo 2 águas pressurizada, $10 \mathrm{~L}$, e 1 de gás carbônico, $6 \mathrm{Kg}$

- Terceiro piso - parte Biblioteca: possui 2 unidades, de 1 água pressurizada $10 \mathrm{~L}$ e $1 \mathrm{CO}_{2} 6 \mathrm{Kg}$. Para este setor seriam necessários 2 extintores de água pressurizada, 10 L, e 2 de gás carbônico, $6 \mathrm{Kg}$.

- Quarto Piso - parte Biblioteca: dispõe de $1 \mathrm{CO}_{2} 6 \mathrm{Kg}$. Para este setor seriam necessários 1 extintores de água pressurizada, 10 L.

- Quarto piso - parte Reitoria: possui 2 unidades, 1 água pressurizada 10L e 1 PQS $4 \mathrm{Kg}$. Para este setor seriam necessários 2 extintores de água pressurizada, $10 \mathrm{~L}$, e 1 de gás carbônico, $6 \mathrm{Kg}$.

- Quinto piso - parte Biblioteca: encontra-se dois unidades, 1 água pressurizada $10 \mathrm{~L}$ e $1 \mathrm{CO}_{2} 6 \mathrm{Kg}$. Para este setor seriam necessários 2 extintores de água pressurizada, 10 L, e 2 de gás carbônico, $6 \mathrm{Kg}$.

Os extintores instalados não possuem sinalizações adequadas.

\section{Sinalização de segurança contra incêndio}

A edificação é desprovida de sistema de sinalização de emergência.

A Sinalização de Segurança contra incêndio e pânico atende as exigências da NBR13434/2004.

As placas de sinalização têm como objetivo orientar as ações de combate a incêndio e facilitar o acesso às rotas de saída para abandono seguro da edificação em caso de incêndio e pânico.

As placas instalação são as do tipo:

- Saída de emergência;

- Alarme;

- Extintor de incêndio;

- Hidrante.

As placas de sinalização de proibição serão instaladas em locais visíveis e a uma altura de $1,80 \mathrm{~m}$, medida do piso acabado. 


\section{Hidrantes}

O Bloco Biblioteca/Reitoria é possui 5 hidrantes instalados, estando alguns obstruídos e em número insuficiente para proteger toda edificação. Foi notado também que não existe reserva técnica de incêndio.

Os Hidrantes da edificação devem atender ao que preconiza a NTCB No19/2015 - Sistema de proteção por Hidrantes e Mangotinhos, de tal forma que em qualquer ponto de área protegida possa ser alcançada, considerando-se no máximo $30 \mathrm{~m}$ de mangueira e6 m.c.a.na ponta do esguicho, totalizando $36 \mathrm{~m}$ de distância, além de, estarem locados á uma distância de afastamento de no máximo $5 \mathrm{~m}$ de portas e escadas.

De acordo com a NTCB 19/2015 deverão ser instalados 12 (doze) hidrantes, os quais serão distribuídos nos prédios da biblioteca/ reitoria.

ABRIGO DE MANGUEIRAS: Os abrigos serão fabricados de materiais metálicos pintados em cor vermelha, terão dimensões de $90 \mathrm{~cm} \quad x \quad 60 \quad \mathrm{~cm} \quad x \quad 17 \quad \mathrm{~cm} \quad$ de profundidade, com mangueiras de $63 \mathrm{~mm}$, $30 \mathrm{~m}$ de comprimento, e esguicho de 19 $\mathrm{mm}$.

utilização exclusiva para acondicionamento de mangueiras para o combate a incêndio.

RESERVA DE INCÊNDIO: De acordo com a Tabela 2 da NTCB 19/2015 será necessária uma reserva de incêndio igual a $72 \mathrm{~m}^{3}$, sendo necessário a instalação de bombas para pressurizar os hidrantes.

\section{Acesso a viaturas}

O Acesso a Viaturas, segundo a Instrução Técnica Nº6/2004 do Corpo de Bombeiro Militar do Estado de São Paulo - Acesso de viatura na edificação, no item 5.2.2.1, para este tipo de ocupação é facultativo o acesso para viaturas. Porem no local não há nenhum tipo de obstrução que impeça o acesso das viaturas de combate a incêndio.

\section{Segurança estrutura contra incêndio}

A Segurança Estrutural contra Incêndio deve atender aos elementos estruturais e de compartimentação que integram as edificações, quanto aos Tempos Requeridos de Resistência ao Fogo (TRRF), para que, em situação de incêndio, seja evitado o colapso estrutural por tempo suficiente, atendendo assim ao previsto na IT $\mathrm{N}^{\circ} 08 / 2011-$ Resistência ao fogo dos elementos de construção do Corpo de Bombeiros Militar do Estado de São Paulo.

A edificação atende as exigências de preconizadas na Instrução Técnica $\mathrm{N}^{\circ} 08 / 2011$.

\section{Controle de material de acabamento}

O Controle de Material de Acabamento fixa as condições a serem atendidas pelos materiais de acabamento e revestimento empregados nas edificações, para que, na ocorrência de incêndio, restrinjam a propagação de fogo e o desenvolvimento de fumaça, devem atender a Instrução Técnica $\mathrm{N}^{\circ} 10 / 2011$ - Controle de materiais de acabamento e revestimento, a qual diz que edificações do Grupo F, devem adotar o material de acabamento com as seguintes classificações:

- Pisos: Classe I, II-A, III-A ou IV-A

- Paredes e Divisórias: Classe I ou IIA

- Teto e Forro: Classe I ou II-A.

Obs: As divisórias não atendem as exigências da IT No10/2011.

\section{Plano de intervenção de incêndio}

O Plano de Intervenção de Incêndio estabelece princípios gerais para $\mathrm{O}$ levantamento de riscos de incêndio, elaboração de planos de intervenção de 
incêndio e padronização das formas de intervenção operacional nos locais de risco, atendendo ao previsto a Instrução Técnica Nº16/2004 - Plano de Intervenção de Incêndio.

O responsável pelo uso da edificação deverá fazer um levantamento de dados, e o mapeamento das áreas de risco, para elaborar o Plano de Intervenção de Incêndio.

O Plano de Intervenção de Incêndio consiste num planejamento prévio para a provável ocorrência de uma emergência, e visa a facilitar o reconhecimento da edificação por parte das equipes de emergência. $\mathrm{O}$ mesmo deverá conter a descrição das possíveis causas de incêndios, orientação aos usuários temporários, treinamento com a população permanente da edificação, buscando garantir a segurança do usuário e também o controle da propagação de incêndios.

\section{Brigada de Incêndio}

A Brigada de Incêndio estabelece as condições mínimas para a formação, treinamento e reciclagem da brigada de incêndio para atuação em edificações e áreas de risco, atendendo a Instrução Técnica do Corpo de Bombeiros Militar do Estado de São Paulo No17/2011 - Brigada de incêndio.

$\mathrm{Na}$ UFMT existe uma Brigada de Incêndio que é treinada para atender ocorrências em qualquer das edificações existentes no Campus de Cuiabá.

\section{CONSIDERAÇÕES FINAIS}

O que diferencia os preventivos da Lei 8399/2005, para construções anterior e posterior a 29 de agosto de 1984 para a edificação em estudo, é que as construções posteriores a esta data tem um acréscimo à quantidade de preventivos a serem analisados e estabelecidos no local, sendo estes: acesso a viatura nas edificações, segurança estrutural contra incêndio, controle de materiais de acabamento, plano de intervenção de incêndio, brigada de incêndio e detectores de incêndio.

Podendo-se verificar que a edificação não cumpre as exigências normativas do Corpo de Bombeiros de Mato Grosso. Logo, os equipamentos de combate a incêndio apresentam irregularidades em suas especificidades, inviabilizando o seu uso em situações de emergências, colocando em risco a integridade física das pessoas, perda do acervo, além de outros bens materiais.

Dentro os preventivos existentes, os extintores locados com distancias corretas, os hidrantes encontram-se obstruídos e locação indevida, as fiações do prédio devem ser refeitas, não há saída de emergências, sinalização, detectores e alarme de incêndio. Porem na universidade há brigada de incêndio atendendo a esta exigência da Lei. Portanto, concluiu-se que é de fundamental importância que o Campus execute projeto de instalação de incêndio e pânico no prédio da Biblioteca e Reitoria.

\section{REFERÊNCIAS}

ABNT. ASSOCIAÇÃO BRASILEIRA DE NORMAS TÉCNICAS. NBR 1389: Glossário de termos relacionados à segurança contra incêndio. Rio de Janeiro, 1997.

ABNT. ASSOCIAÇÃO BRASILEIRA DE NORMAS TÉCNICAS. NBR 10898: Sistemas de iluminação de emergência. Rio de Janeiro, 1999.

ABNT. ASSOCIAÇÃO BRASILEIRA DE NORMAS TÉCNICAS. NBR 13434-1: Sinalização de segurança contra incêndio e pânico. Parte 1: princípios de projeto. Rio de Janeiro, 2004.

ABNT. ASSOCIAÇÃO BRASILEIRA DE NORMAS TÉCNICAS. NBR 13434-2: Sinalização de segurança contra incêndio e 
pânico. Parte 2: símbolos e suas formas, dimensões e cores. Rio de Janeiro, 2004.

ABNT. ASSOCIAÇÃO BRASILEIRA DE NORMAS TÉCNICAS. NBR 13714: Sistema de hidrantes e de mangotinhos para combate a incêndio. Rio de Janeiro, 2000.

ABNT. ASSOCIAÇÃO BRASILEIRA DE NORMAS TÉCNICAS. NBR 14276: Brigada de incêndio - requisitos. Rio de Janeiro, 2006.

ABNT. ASSOCIAÇÃO BRASILEIRA DE NORMAS TÉCNICAS. NBR 17240:

Sistema de detecção e alarme de incêndio projeto, instalação, comissionamento e manutenção de sistema de detecção e alarme - requisitos. Rio de Janeiro, 2010.

BREnTAnO, Telmo. A Proteção Contra Incêndio no Projeto de Edificações. 1.ed. Porto Alegre, 2007.

CAMPOS, Patrícia Alana S. Avaliação em Edifício Público das Instalações de Prevenção, Combate a incêndio e Pânico. 2013. Monografia (Conclusão de curso), Engenharia Sanitária e Ambiental, Universidade Federal do Mato Grosso, Cuiabá, 2013.

CAMILO, Abel B. Manual de Prevenção e Combate a Incêndio. 11. ed. São Paulo: SENAC, 2011.

CARAMUJO, Maria Cristina P. Gestão da Segurança contra Incêndio em Cidades Sustentáveis.Dissertação (Mestrado em Construção e Restabilidade), Instituto superior técnico, Universidade Técnica de Lisboa, Lisboa, 2012.

FERNANDES, Ivan Ricardo. Engenharia de Segurança Contra Incêndio e Pânico. 1 ed. Curitiba: CREA-PR, 2010.

FREIRE, Carlos Darci R. Projeto de Proteção Contra Incêndio (PPCI) de um prédio residencial no centro de Porto Alegre.2009. Disponível em: $<$ http://www.lume.ufrgs.br/handle/10183/2 7114> Acesso em: 06 dez. 2015.

GOMES, Ary G. Sistema de Prevenção contra Incêndio. Rio de Janeiro: Interciência. 1998.

LEITE, Yuri L; ASSIS, Edílson M. Segurança Contra Incêndio e sua Importância em Patrimônios HistóricoCulturais.2009. Disponível em: $<$ http://scholar.google.com.br/scholar?q=S EGURAN\%C3\%87A+CONTRA+INC\%C 3\%8ANDIO+E+SUA+IMPORT\%C3\%82 NCIA+EM+PATRIM\%C3\%94NIOS+HIS T\%C3\%93RICOCULTURAIS +++Yuri+L ima+Leite++Ed\%C3\%ADlson+Machado+

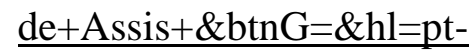

BR\&as_sdt=0\%2C5> Acesso em: $06 \mathrm{dez}$. 2015.

MATO Grosso (Estado). Decreto n. 857, de 29 de agosto de 1984. Dispõe sobre especificação para instalação de proteção contra incêndio.

MATO Grosso (Estado). Lei n. 8399, de 22 de dezembro de 2005. Dispõe sobre lei de segurança contra incêndio e pânico de Mato Grosso.

MATO Grosso (Estado). Norma Técnica do Corpo de Bombeiros No01/2008. Procedimentos administrativos.

MATO Grosso (Estado). Norma Técnica do Corpo de Bombeiros No $13 / 2013$. Procedimentos administrativos.

MATO Grosso (Estado). Norma Técnica do Corpo de Bombeiros No19/2015. Procedimentos administrativos.

MATO Grosso (Estado). Portaria n. 0001. Dispõe sobre adoção normas técnicas para padronização dos serviços de segurança contra incêndio e pânico no âmbito do CBM/MT. 2011. 
MELO, Eduardo. A. L. Curso de Instalações prediais de proteção contra incêndio. FINATEC. Brasília, DF, 1999.

MORAES, Jerté Z. Projeto de Prevenção e Combate a Incêndio na Indústria Química. Dissertação (Especializaçãoem Engenharia de Segurança do Trabalho), Pós-graduação, Universidade do extremo Sul Catarinense, Criciúma, 2012.

MOREIRA, Katia Beatris R; ONO, Rosaria. As Intervenções da Segurança Patrimonial nos Projetos Arquitetônicos. Disponível em: <http://www.usp.br/nutau/CD/56.pdf>

Acesso em: 08 dez. 2015.

NUNES, Daniel P. Plano de Prevenção e Proteção Contra Incêndio do Prédio Central de uma Escola Técnica Pública: Adequação à Lei Complementar $\mathbf{N}^{\mathbf{0}}$ 420/98 do Município de Porto Alegre. 2009. Disponível em: <http://www.lume.ufrgs.br/handle/10183/2 5189> Acesso em: 14 dez. 2015.

ONO, Rosaria. Proteção do Patrimônio Histórico-Cultural contra Incêndio em Edificações de interesse de Preservação. $2004 . \quad$ Disponível em: <http://www.casaruibarbosa.gov.br/dados/ DOC/palestras/memo_info/mi_2004/FCR B_MemoriaInformacao_RosariaOno.pdf> Acesso em: 01 dez. 2015.

ONO, Rosaria. .Parâmetros para Garantia da Qualidade do Projeto de Segurança Contra Incêndio em Edifícios
Altos. 2007. Disponível em: <http://seer.ufrgs.br/ambienteconstruido/ar ticle/view/3731/2083 > Acesso em: $01 \mathrm{dez}$. 2015.

PEREIRA, Aderson G. Segurança contra Incêndio. São Paulo: EMTS Seguros LDTA. 2000.

SÃO Paulo (Estado). Instrução Técnica. $\mathrm{N}^{\circ} 02 / 2011$. Conceitos Básicos de Segurança contra Incêndio.

SÃO Paulo (Estado). Instrução Técnica. $N^{\circ} 03 / 2011$. Terminologia de Segurança contra Incêndio.

SÃO Paulo (Estado). Instrução Técnica. $\mathrm{N}^{\circ} 06 / 2011$. Acesso de Viatura na Edificação e Área de Risco.

SÃO Paulo (Estado). Instrução Técnica. $N^{\circ} 08 / 2011$. Resistencia ao Fogo dos elementos de Construção.

SÃO Paulo (Estado). Instrução Técnica. $\mathrm{N}^{\circ} 10 / 2011$. Controle de Materiais de Acabamento e de Revestimento.

SÃO Paulo (Estado). Instrução Técnica. $N^{\circ} 14 / 2011$. Carga de Incêndio nas Edificações e Áreas de Risco.

SÃO Paulo (Estado). Instrução Técnica. $N^{o} 16 / 2011$. Plano de Emergência contra Incêndio.

SEITO, Alexandre I. Segurança Contra Incêndio no Brasil. São Paulo: Projeto Editora, 